
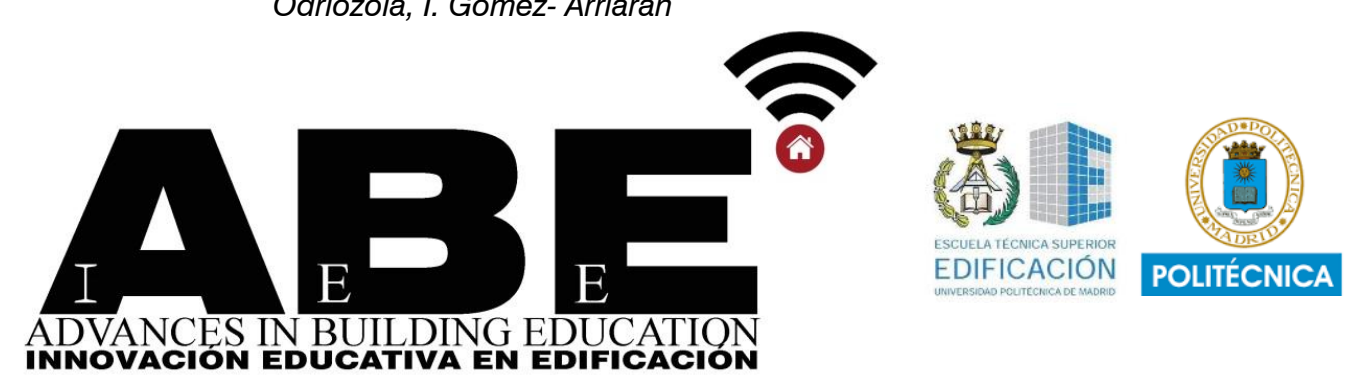
INNOVACION EDUCATIVA EN EDIFICACION

\title{
Energy Savings and Efficiency at Secondary School Buildings. (ElhZA+ENEDI PROYECT)
}

\author{
A. Picallo-Perez'1, J.M. Sala-Lizarraga' ${ }^{1}$, C. Escudero-Revilla', A. Lasa-Iglesias ${ }^{2}$, D. Solabarria ${ }^{2}$, J.M Hidalgo', N. \\ Romero', M. Odriozola', I. Gomez- Arriaran'. \\ ${ }^{1}$ Research group ENEDI, Department of Thermal Engineering, University of the Basque Country (UPV/EHU); Alameda \\ Urquijo, S/N, 48013 Bilbao, Vizcaya, Spain \\ ana.picallo@ehu.eus \\ ${ }^{2}$ Elhuyar Fundazioa. Zelai Haundi kalea, 3, Osinalde industrialdea, 20170 Usurbil, Gipuzkoa
}

\section{Recibido: 15/05/2021 | Aceptado: 23/07/2021 | Fecha de publicación: 28/08/2021} DOl:10.20868/abe.2021.2.4721

\section{HIGHLIGHTS}

- Students and university professors research together on energy in buildings

- Energy efficiency actions are promoted in schools

- Female references are visualized to encourage STEM vocations among students.

- The student goes from being a mere spectator to being the main researcher. 


\section{ABSTRACT}

This work describes the project submitted to the University-Society-Business 2021 call for proposals whose aim is to integrate the knowledge and university practices in the field of energy in buildings into secondary school students. The aim is to define the energy strategies to be implemented to strengthen the relationship between secondary education and university studies, by means of a "pilot project" at a secondary school, as well as to promote Science, Technology, Engineering and Maths (STEM) scientific vocations in young people, with particular emphasis on the female gender. The project will carry out an energetic study at a school developed by university research staff and secondary school students. The aim is to motivate and confirm the qualities of people in STEM teaching, to arouse interest and closeness as well as to promote education in the subject of energy efficiency in buildings.

Keywords: University and secondary school student agents; energy efficiency in buildings; STEM education; girls in technical education.

\section{INTRODUCTION}

This work describes the project, presented in the University-Society-Business 2021 call of University of the Basque Country (UPV/EHU), which will be carried out between members of the Elhuyar Foundation and the ENEDI Research Group of the UPV/EHU, with the aim of integrating university knowledge and practices in the subject of energy in buildings into society (precisely, the young society). This work intends to mark the strategies that will be carried out to strengthen the relationship between secondary education and university studies, as well as to promote scientific vocations in young people, with special emphasis on the female gender. Energy efficiency in buildings is in the spotlight.

Therefore, two lines of action are distinguished that converge in the same project: (1) energy efficiency in buildings and (2) the need to motivate students, breaking the stereotypical gender roles in the engineering field, to bring them closer to the world of university.

\subsection{Background in the field of energy efficiency in buildings}

Residential buildings and tertiary servicebuildings occupy the third position among the consumers of final energy, after the transport sector and the industrial sector, and they are responsible for $29.5 \%$ of the energy consumption [1]. Therefore, the research for energy savings in the building sector is a key pillar for achieving the objectives of a sustainable and balanced society.

However, the building sector includes a wide range of actors, from professional architects and engineers, technicians and building trades, etc., to the end user of the building. This fact makes it necessary to transmit knowledge between the people involved in the development of energy efficiency and those who consume the good, both to optimize energy use and to raise awareness and develop knowledge towards a sustainable community.

It is therefore necessary to involve all actors in the sector to make an efficient use of energy. Nevertheless, above all, society must be trained from an early age, in a practical and didactic way since experiential learning is crucial for the correct use and dissemination of knowledge. In this regard, the secondary education curriculum of the Basque Autonomous Community explicitly 
includes the topic of energy efficiency in the section of "Energy and changes" [2].

It should be remembered that adolescence is a decisive stage for young people; it is the period in which they begin to develop their autonomy and their own criteria, and, therefore, an ideal stage to understand and deepen their understanding of social development and energy sustainability matters. At the same time, it is a period when, in general, the decrease in self-esteem, especially in the case of girls, can have a negative influence on their choices. Training young people in the technical and energy field means improving their competitiveness and the competitiveness of the community.

\subsection{Background from the field of STEM education}

The term STEM is an acronym that stands for Science, Technology, Engineering and Maths; it is a learning model based on teaching those disciplines in an integrated way rather than in separate subject areas, with an interdisciplinary and applied approach.

It is expected that Europe will need more scientists and technologists in the short term, and that there will not be enough qualified workers to fill these positions. Therefore, one of the main objectives of the European Union is to promote the scientific and technological vocations demanded by the labour market. According to data provided by Eurostat [3]:

- In 2017 among the 18 million scientific and engineering people in Europe 59\% were men and $41 \%$ women.

- The presence of men (83\%) in the manufacturing industry in high-level and midlevel technologies is much higher than the presence of women; however, in the services sector the presence of both sexes is more balanced ( $55 \%$ men and $45 \%$ women).

Moreover, $80 \%$ of the jobs of the future will require STEM skills to meet the challenges of achieving a sustainable world in all economic sectors.

Even though this demand exists, the forecasts made on the professional aspirations of young people are not enough to cover these needs and the situation is especially serious in the case of girls (for more information see the document [4]).

As for the situation in the Basque Country, according to data provided by EUSTAT, we find the following situation:

- Within a decade, there will be $10 \%$ fewer boys and girls in the classroom (up to the age of 16).

- Only $54 \%$ of high school students choose a scientific-technological education; therefore, in four years, $16.6 \%$ fewer students will have enrolled in STEM studies.

- Thirty-nine percent of students coming from professional-formation and university obtained a STEM degree. In addition, only $9 \%$ of girls coming to professional formation and $31 \%$ of those coming to university choose a STEM track.

- However, in the last two years, there has been a $56 \%$ increase in the number of companies requesting STEM profiles from professional training and a $25 \%$ increase in the number requesting STEM profiles from university.

Moreover, as stated in the 2019 UNESCO report 'Cracking the Code. Girls' and women's education in science, technology, engineering, and mathematics (STEM)", the situation of women in the world with respect to STEM studies can be summarized as follows: girls, as early as 
primary education, lag behind in education and in games related to STEM subjects; in higher education, that gap increases. Moreover, they increasingly lose interest in early and late adolescence. As a result, girls make up only $35 \%$ of STEM higher education. In terms of female representation, the differences in STEM education from state to state are very large, which seems to suggest that contextual factors play a crucial role. The level of dropout in STEM disciplines is much higher among women both during the college years and in professional activity.

Therefore, the need to reverse this trend is evident and forces interdisciplinary people (people from the university or elHuyar) to play an active role.

\section{2. OBJECTIVES}

The motivation of this work is focused on the identification of energy as a priority in the field of intelligent society, proposing initiatives based on the dissemination of theoretical and practical knowledge of energy saving techniques at schools-buildings. The main idea is to promote scientific-technological experiences involving the community, that is, with the participation of students and university professionals to build bridges and foster the relationship between the educational system and the professional world. The objective is to bring young people closer to real references, models, and professions in the STEM field, precisely in the energy efficiency area of buildings.

To this end, the aim is to characterize the energy performance of the school building by means of practical tests and to obtain the energy certificate of the building. It is based, therefore, on involving the younger society to carry out actions of efficiency and energy saving. The research will be carried out at a specific school centre, which will lead to replication plans, to be easily extended to the whole school sector. That is why this ElhZA+ENEDI project will generate knowledge, based on energy techniques, among the younger society, through the interaction of the UPV/EHU with the Elhuyar Foundation. The aims are:

To raise the students' level of knowledge in terms of sustainability and energy saving in buildings, understood as a good.

To promote energy efficiency techniques and the use of renewable energies, as an element of competitiveness and improvement of social welfare, focused on building thermal systems.

To contribute to the transfer of knowledge and awareness of energy use in buildings from an early age and to stimulate and strengthen relations between the university, the Elhuyar Foundation and society in general.

To train students in autonomy and encourage their motivation to empower them to meet the challenges of energy efficiency.

Likewise, the general objectives of the project are aligned with the STEM Euskadi strategy, promoted by the Department of Education of the Basque Government, which sets out the following objectives:

To promote scientific-technical education and training at all stages of education, and, to include socio-economic professional stakeholders in the work.

To arise the vocation and the desire to dedicate oneself professionally to STEM, energetic disciplines from primary education and paying special attention to girls, to prepare students for future challenges. 
To promote the dissemination and scientifictechnological culture among Basque citizens.

\section{RELATED WORKS AND INFRASTRUCTURE}

This project is based on the involvement of young people in the field of energy efficiency in buildings. Therefore, on the one hand, the experience of the ENEDI research group is based on the characterization and optimization of energy in buildings, and, on the other hand, elHuyar has an extensive experience in promoting STEM subjects among young people.

\subsection{ENEDI: energy efficiency in buildings}

The ENEDI research group was set up in 2005, because of the Agreement signed between the Housing Department of the Basque Government and the UPV/EHU. By virtue of this agreement, ENEDI oversees the management and development of the Thermal Area of the Laboratory for Quality Control in Building of the Basque Government (LQCB), [5].

LQCB aims to contribute to the improvement of the energy quality of buildings by carrying out characterization tests of materials and construction elements, technical advice to the agents of the sector, support to the institutions in the elaboration of regulations, promotion, and dissemination of quality in manuals and databases, etc.

The activities of the Thermal Area were focused on the analysis of the thermal behaviour of the building envelope. For this purpose, the LQCB is equipped with the appropriate technical means, such as: heat flow and hot plate conductivity meters, DSC equipment for measuring specific heats of materials, two guarded hot box equipment for measuring thermal transmittance of opaque and semi-transparent enclosures, tracer gas equipment for measuring ventilation flow rates, thermography equipment, two Paslink cells for thermal characterization tests of special construction elements, etc.

Some of these equipment will be used to carry out the energy audit tasks of the school-building.

\subsection{EIHuyar: STEM Education promotors}

In Elhuyar they have been working for several years in STEM education under the slogan "Experiences and community". In this context, they have created the Elhuyar Zientzia Azoka (science fair) action, which has become a dynamic initiative among the school community, through which young people from 12 to 18 years of age carry out scientific and technological projects during the academic year. The event has become a key event for the educational community, achieving the recognition of the STEM Euskadi Award in the category of Most Innovative STEM Education Initiative.

\section{METHODOLOGY}

The ElhZA+ENEDI project is innovative and differs from existing projects in the environment. It aims to carry out a "pilot case" to integrate energy efficiency actions in schools, with the help of researchers, as well as students and teachers, in a practical and didactic way to promote knowledge and the rational use of energy in buildings.

This pilot case will facilitate scalability and aims to be replicable in other centres to achieve maximum social and environmental impact. Therefore, a great capacity for replication is required, to be able to scale the results to other schools, thus contributing to mitigate, as far as possible, the unnecessary consumption of natural resources and, educating in a ludic way in the field of energy efficiency to the youngest 
members of society, breaking gender roles and stereotypes in STEM subjects.

Hence, this project foresees to address these challenges through a set of general implementation phases:

- Phase 1: Informative talks to raise and stimulate theoretical knowledge of energy saving and efficiency in buildings. The idea is to establish contexts for dialogue between professionals and students, seeking the involvement of students and offering a space to form an opinion and express it to the research staff.

- Phase 2: In-situ tests to put into practice the knowledge acquired and to evaluate the energy status of the school, involving the students through work projects. This phase is crucial to promote the autonomy and motivation of students towards scientific-technical subjects and energy savings in buildings.

- Phase 3: Propose energy improvement actions to promote the energy efficiency of the school building.

- Phase 4: Identification of best practices and replicable models, to extend the practice to other schools.

- Phase 5: Sensitization, training, information, etc., directed to the school community to promote student motivation towards technical subjects and energy efficiency in buildings.

- Phase 6: Dissemination of results, both by professionals and students at congresses, science fairs, etc., using all the results of the project to promote continuously energy efficiency and the motivation of society in the subject of efficient energy use in buildings

\section{GENERAL STRUCTURE OF THE WORK}

In addition to project management, which aims to monitor the progress of ElhZA+ENEDI activities and to ensure the proper development of the project, practical lessons are given, tests are carried out and energy improvement actions are incorporated.

The informative process to promote knowledge in the field of energy efficiency is based on the realization of divulgative talks to increase the knowledge of students and schoolteachers on issues related to energy efficiency in buildings. This section introduces the buildings demands, focused on the school environment, to have an impact on the reduction of consumption. Basic ideas about energy certification and methodologies for calculations and experimental tests are introduced. The voice of the students will be considered during the formation, both the previous ideas and the development of their competences, which will be integrated in the curriculum of the centre.

After the informative process, the various research projects of the school groups will be launched. The global challenge and subchallenges that the students will have to tackle will be established, accompanied by experts in the field, and the various technological projects of the different teams that will be created at the school to participate in Elhuyar Zientzia Azoka (science Fair) will be "framed".

Afterwards, in-situ tests will be carried out to characterize the school centre energetically. The objective is twofold: on the one hand, it is to energetically model the school centre, through experimental tests, such as "in situ" measurements of the thermal transmittance of the building envelope, or the measurement of 
infiltrations by blow door test [6], to know the air renewal in the building. On the other hand, it seeks the involvement of students to actively participate in the experimentation.

Thermal characterization experiments will be carried out to verify and measure in a practical way the knowledge acquired. This is a key task for students to progress in self-learning and autonomy, to increase their confidence and develop a scientific-technical project, with the help of a mentor or professional in the field.

Based on the results obtained from the tests, energy improvement actions will be proposed, both in the envelope and in the thermal installations of the school. The people in charge of carrying out the core of this task will be the researchers, although the involvement of the students will also be encouraged, to make them participants and accomplices in energy efficiency enhancement activities.

The students will draw the conclusions, advised by the research personnel, and will prepare the materials to show the results of the project, namely the final report, video presentation of the project, presentation, etc.

One of the main objectives of the subsequent replicability is to scale it to other schools. For this, a replication methodology will be analysed based on all the knowledge of the previous phases and the experience acquired with the project.

Dissemination of the project will also be essential to involve future research and other secondary schools in energy efficiency. The idea will be to promote the advanced techniques developed throughout the project and increase their replicability. Therefore, students will be proposed to participate in visualization actions such as Elhuyar Zientzia Azoka, Bizilabe fairs and other events to socialize the research of school groups, science week, etc.

\section{RESULTS}

Promoting energy efficiency in the building and services sector is essential, given the high energy and environmental requirements of current European directives. In addition, school buildings are large consumers of energy, but with great potential for savings. If renovation techniques are applied to improve the building envelope and renewable technologies are integrated, it is possible to achieve a nearly zeroenergy building, reducing to a minimum the impacts generated for air conditioning and indoor comfort.

To carry out this practice it is essential to generate knowledge and awareness in the field of energy efficiency in buildings, starting at an early age, and extending the knowledge to the whole society, for a sustainable use of natural resources. Likewise, we want to involve young people in STEM practices to revalue their use and dissuade stereotypes linked to STEM sciences. Therefore, dissemination and exploitation strategies are basic to increase the impact of the results achieved and to attract the interest of other schools, as well as to promote future research derived from this project.

Consequently, the knowledge generated during the project will be the basis for future replication of the project's results. Therefore, this project is intended to be the "pilot example" of a subsequent long projection.

The results, as well as the knowledge gained during the ElhZA+ENEDI project, will be used to define the potential for replication and the methodology for scaling it up. In addition, the idea is to move forward together with other similar initiatives to better exploit synergies and 
strengthen the dissemination of good practices, results, and visibility; but, above all, to integrate the younger society in STEM techniques and energy efficiency in buildings.

\section{CONCLUSIONS}

The ElhZA+ENEDI project proposed in this paper aims to involve young people in buildings energy efficiency projects to positively influence the rational use of energy and sustainability.

Technical education receives special attention given the industrial and social need for people trained in this field. However, fewer, and fewer people are enrolling, and the gender gap is still significant, due to the low percentage of women involved in these areas.

STEM techniques aim to bring younger people closer to scientific subjects such as science, technology, engineering, and mathematics. Linking secondary school students with these fields is essential to generate interest and motivation to choose a professional future, as well as to demonstrate that these are not selective sciences for a specific social group, but are suitable for girls, boys, or non-binary people.

This paper defines the ElhZA+ENEDI project, which is an institutional strategy to connect secondary education and university, in the field of energy and building engineering. The project is carried out between the ENEDI research group of the EHU/UPV and the ElHuyar foundation and aims to carry out an energy study at a school building by means of university specialists and the students of the centre.

Therefore, the project aims to promote values linked to science, technology, and innovation among young people, as well as to increase the scientific culture of society, generating links between the education system, the scientific community, families, and society in general, to give a more realistic image of science and technology, and thus positively influence the STEM positioning of young people. In short, it wants to contribute to young students, and especially groups underrepresented in STEM professions, to perceive themselves in the future in a possible STEM profession.

Thus, the project seeks to offer "scientific experiences" to young students, with the direct involvement of a real research team based on the search for energy efficiency in buildings.

\section{REFERENCES}

[1] IDAE, Instituto para la Diversificación y Ahorro de la Energía. Gobierno de España. Guía Práctica de la Energía. Consumo eficiente y responsable.

[2] Basque Government. Department of Education, Language Policy and Culture. Basic Education Curriculum. Guidance curriculum that completes Annex II of the Decree on Basic Education. 236/2015 (in Spanish)

[3] Government of Spain. Ministry of Science, Innovation and Universities. SCIENTIFIC WOMEN IN FIGURES 2017. Statistics and indicators of gender (in)equality in scientific training and profession. (In Spanish)

[4] EIHuyar STEM education and STEM careers, a source of inspiration for young people, Elhuyar 2020. STEAM Hezkuntza eta STEM profesioak, gazteak inspiratzeko (in Basque)

[5] https://www.euskadi.eus/gobiernovasco/laboratorio-control-calidad-vivienda/

[6] Martín-Garín, A., Millán-García, J. A., HidalgoBetanzos, J. M., Hernández-Minguillón, R. J., \& Baïri, A. (2020). Airtightness Analysis of the Built HeritageField Measurements of Nineteenth Century Buildings through Blower Door Tests. Energies, 13(24), 6727 